\title{
Ten Years of WIND: an information brokers' success story
}

WIND, Wissenschaftlicher Informationsdienst (Scientific Information Service) was founded on 22 May, 1984. Originally the firm was engaged in informationbrokerage and in running a laboratory for biological and chemical analysis.

After a restructuring in 1987 a WIND-office was opened in the Cologne Technology Parc Centre for Founding and Innovation. The decision of taking part in a federal program for information brokerage (1987-1990) made it possible to enlarge this field of activities as well as the permanent staff.

In 1986 WIND started to work on online-training and thus acquired a second activity-field besides information brokerage. Since 1990 WIND runs its own training facilities in the Cologne Technology Parc, in which the training courses are held. Apart from this the facilities are frequently hired by hosts and producers of databases to run their respective presentations and trainings. Training courses were also given in cooperation with partners in different other places. WIND is holding over 100 seminar days per year and it has thus become the leading player among independent organisers of online-trainings.

Among other activities WIND provides training courses for the examiners of the German and Swiss Patent Offices. WIND has elaborated the basic training course for the Questel retrieval language, Questel plus. Moreover, four handbooks for the DIMDI-databases and the basic as well as the advanced training curriculum for the GENIOS trip retrieval system, supplemental by two special courses were worked out from the very beginning until the printing level. Since 1988 a seminar for the retrieval of environmental information is offered yearly in cooperation with the German Federal Environmental Authority.

October 1992 saw the beginning of a regional partnership for the area of Cologne, Bonn and Aachen with the host for German legal information, JURIS. WIND is thus the exclusive partner for JURIS clients in the field of training, retrieval assistance and technical support. In close cooperation with providers of computer and datatransmission equipment for online workstations, combined with self-developed bench-marking tests for research work places, WIND runs the "department of consultation and installation of online workplaces" and generates a specific interest in these times of reduced budgets and cut-down online departments.

WIND was also present at the International Aeronautical Exhibition, ILA, at Berlin from May 28 till June 5, 1994. 